\section{TREATMENT OF RUBBER INDUSTRY WASTEWATER BY USING FENTON REAGENT AND ACTIVATED CARBON}

\author{
Tuty Emilia Agustina* , Elon Jefri Sirait, Herman Silalahi
}

Chemical Engineering Department, Sriwijaya University, Indralaya, 30662, Indonesia
Article history

Received

10 March 2017

Received in revised form

18 July 2017

Accepted

6 September 2017

\section{Graphical abstract}
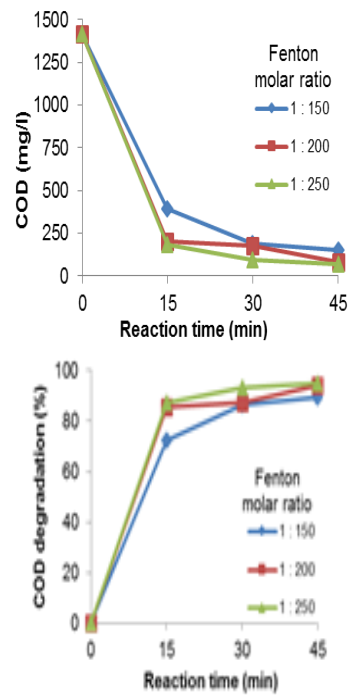

\begin{abstract}
Rubber industries are sufficiently developed and widely spread countryside as well as in some big cities in Indonesia. An Increasing number of rubber industries have also increased rubber wastewater. However, the rubber industry development should pay attention to the impact on the environment. The rubber wastewater is problematic, because of high Chemical Oxygen Demand (COD) content. So far, the methods that have been used to remove COD in the waste water have been proven to be costly and time consuming. The research objective is to treat the rubber wastewater by using a combination of Fenton reagent and activated carbon adsorption. In this study, effect of molar ratios of Fenton reagent, $\mathrm{pH}$, and reaction time on $\mathrm{COD}$ degradation were studied. After treating with Fenton reagent, the wastewater was passed into an adsorption column of $20 \mathrm{~cm}$ height of activated carbon granules. The maximum COD degradation of $95 \%$ were found by using a combination of Fenton reagent and activated carbon, with a molar ratio of reagent Fenton 1:250 and a reaction time of 45 minutes. The final COD of $71 \mathrm{mg} / \mathrm{l}$, TSS of $70 \mathrm{mg} / \mathrm{l}$, and $\mathrm{pH}$ of 7.8 were found which fulfilled the environmental quality standard regulation for industrial wastewater in Indonesia.
\end{abstract}

Keywords: Rubber industries, Fenton reagent, activated carbon adsorption

(c) 2017 Penerbit UTM Press. All rights reserved

\subsection{INTRODUCTION}

Nowadays, $70-80 \%$ raw rubber produced in the world stock in South East Asia, originates primarily from Thailand, Malaysia and Indonesia [1]. Rubber industries play an important role for human life, because the role of these industries to meet the many needs of human beings. Rubber products such as rubber tires, rubber bands, rubber thread, eraser, and so on, was produced from the rubber industry. Rubber industry will be increasingly necessary given the growing human population and the increasing human need, the production activities will increase. Industrial activities in addition to provide a positive impact for the economy, also has an impact on the environment.

Even though very much profit of natural rubber latex manufacture, its production discharges a considerable amount of effluent into environment from several treating stages i.e. coagulation, grinding, centrifugation, washing, dehydrating, and other mechanical manufacturing. A significant amount of effluent is produced, which is contain strong color and very poisonous, a great volume of suspended solids, a very unstable $\mathrm{pH}$, high temperature, COD, $B O D$, etc. [2]. If the wastewater is place straight into water bodies such as surface waters wells, any streams, ponds or even the ocean without treatment at all, it will essentially contaminate the water. The disposal of these effluents into community water region can contribute to thoughtful reduction of dissolved oxygen, thus disturbing the standard environmental condition for supporting the aquatic system [3].

Rubber manufacturing industries consume large volume of water and chemicals for processing of rubber. Mostly, there are three main pollutants 
originating from the natural rubber latex production created in the wastewater effluents: latex, organic matter and nitrogen-containing substances [4]. Characteristics of process effluents from rubber processing industries were reported by [3], as can be shown in Table 1.

Wastewater collected from rubber manufacturing industries was characterized for their pollution by another researcher in 2014. The results of the analysis reported that the total dissolved solids (TDS) were $2240 \mathrm{mg} / \mathrm{l}$, total suspended solids (TSS) were 3512 $\mathrm{mg} / \mathrm{l}$, ammonia and phosphate were 94 and 48 respectively, which were high when related to effluent discharge quality standard for industrial wastewater. The biochemical oxygen demand (BOD) and chemical oxygen demand (COD) were 1340 and $2834 \mathrm{mg} / \mathrm{l}$ respectively, which showed that the wastewater was high in contamination potentials and requisite to be treated before discharged to the environment [5]. Discharge of the wastewater in a straight line into the environment without any suitable process treatment will have a severe influence to the environmental stability. That's why the rubber industry wastewater have to properly treat before release to the environment.

Table 1 Characteristics of process effluents from rubber processing industries [3]

\begin{tabular}{lc}
\hline Parameter & Typical range \\
\hline $\mathrm{pH}$ & $3.5-5.5$ \\
Biological Oxygen Demand & $1500-7000$ \\
Chemical Oxygen Demand & $3500-14000$ \\
Suspended Solids & $200-700$ \\
Total Nitrogen & $200-1800$ \\
Sulphate & $500-2000$ \\
\hline
\end{tabular}

All units are $\mathrm{mg} / \mathrm{l}$, except $\mathrm{pH}$

There are various techniques approached can be applied in handling of rubber wastewater in several industries, however, a number of boundaries still happen. In common, the technologies of wastewater treatment of natural rubber manufacturing in South East county are based on conservative biological processes, for example: lagoon system, oxidation ditch, anaerobic digestion and activated sludge [4]. The pond system costs least particularly due to the misplaced operation costs. But, this process involves a large assembly space, has vigorous smell and is dangerous to the ground water without carefully layer and waterproofing the pond. This process is fit for less polluted wastewater and it should not be functioned near domestic regions. Oxidation ditch process is stable, highly efficient for the removal of Nitrogen-containing pollutants and organic matter in rubber processing wastewater. This process is useful to treat a high concentration pollutants of wastewater, especially the one with high content of ammonia. However, put on and functioning this method require special situations such as high qualified manual labor, a high operation costs and periodic maintenance were needed. Another methods widely practical are anaerobic digestion and activated sludge treatment because of the low operation cost and their efficiency in treating organic matter. However, these processes require considerable time of treatment.

The highest problematic of wastewater treatment of rubber handling manufactories in South East region, including in Indonesia, is the inefficiency of the technologies applied [4]. For example, the biological based technologies including up-flow anaerobic sludge blanked (UASB), activated sludge, oxidation ditch etc. do not have sufficient capability to eliminate Nitrogen-containing contaminants entirely. Also in such biological method, the microorganism's community maintenance is not easy and the microorganism generally decease because of the great organic content of rubber industrial wastewater. Additionally, the conservative decantation method is typically burdened, thus the concentration of uncoagulated particles in rubber wastewater effluent is very high. This matter will generate problems for the next handling processes.

The typical biological treatment do not have satisfactory capacity to come across the quality standard for the effluent of natural rubber manufacturing. To date application of biological, physical and chemical combination method for eliminating of mayor contaminant in rubber industry wastewater has not been reported. As a result, many advanced technologies are being investigated to achieve better effluent standard such as coagulation-flocculation, flotation, membrane, ozonation, etc. in order to arrange for cost-effective resolutions and high elimination efficacy.

Currently, the membrane bioreactor (MBR) technology can overcome the disadvantages of biological systems. This technology had been researched for the treatment of rubber latex processing wastewater. The results of the research done by [6] exposed that the optimum flux of method was attained at $0.009 \mathrm{~m}^{3} / \mathrm{m}^{2} \mathrm{xh}$ and at this flux rate, the method could be continuously functioned more than one month without the chemical substance washing of membranes. At the initial concentration of $3,500 \mathrm{mg} / \mathrm{L} \mathrm{COD}$, the elimination efficiency of COD $96.99 \%$, BOD $96.78 \%$, total-N $65.17 \%$ and NH3 $61.35 \%$ were accomplished. On the other hand, innovative advanced oxidation processes (AOPs) demonstrate great potential in various wastewater treatment application areas. AOPs have many benefits in wastewater treatment because they can be useful for general organic content decrease, particular contaminant destruction, sludge treatment, increasing bioavailability of refractory organics and color \& odor reduction [7]. The ozonation, as one of AOPs technologies, able to breakdown non-biological organic substances which have a large molecular 
weight into smaller organic substances. Additionally, ozonation method can reduces oxygen demanding matter, eliminate odors, turbidity and surfactants; increases dissolved oxygen and increases suspended solids reduction. Ozone is one of the most active, readily available oxidizing agents, which can transform ammonia into the nitrate. Ammonia found in wastewater as nitrogen pollutant. However, a high capital costs, high electricity consumption, and highly corrosive were the disadvantages of ozonation. A major limitation of the ozonation method is the moderately high cost of ozone generation, course coupled with a very short half-life period of this oxidation agent. And one solution to overwhelmed the those disadvantages is to apply ozone in combination with other methods such as hydrogen peroxide, ultraviolet irradiation/ultrasonic, etc. [8]. Thus, ozonation method is considered as an advanced method for handling of rubber latex treatment. Reference [9] reported by using ozonation process combined with batch activated sludge process (BAS), the optimal conditions for the removal of pollutants are $66.44 \mathrm{mg} \mathrm{O}_{3} / \mathrm{l} \mathrm{O}_{2}$ of ozone concentration, $\mathrm{pH} 9$ and the contact time of 30 minutes, in their study on the removal of biological matter and ammonia.

AOPs have revealed great potential in treating contaminants at low and high concentration and have been employed for treatment of water, wastewater, odors, and sludge [10]. These AOPs utilize the very strong oxidizing power of hydroxyl radicals $(\mathrm{HO} \cdot)$ to oxidize organic substances to the preferred end products of carbon dioxide and water. One method of AOPs also widely used in wastewater treatment is Fenton reagent. Fenton's reagent oxidation is a homogeneous catalytic oxidation process using a mixture of hydrogen peroxide and ferrous ion. The overall reaction is [11]:

$$
\mathrm{Fe}^{2+}+\mathrm{H}_{2} \mathrm{O}_{2} \rightarrow \mathrm{Fe}^{3+}+\mathrm{HO}^{\bullet}+\mathrm{HO}^{-}
$$

Fenton reagent is an attractive oxidative method for wastewater treatment due to the fact that iron is very abundant and nontoxic and hydrogen peroxide is easy to handle and environmentally safe. The leading advantage of the Fenton's reagent is its simplicity. The chemicals are readily available at moderate cost and there is no necessity for special equipment [8]. This method could be a good option for treating the rubber wastewater. Fenton reagent is expected to reduce the content of COD and BOD of wastewater. Due to the high content of solids in rubber wastewater, activated carbon was used as an adsorbent in this research to achieve TSS and $\mathrm{pH}$ values that meet environmental quality standards. The objective of this research is to study the treatment of rubber industry wastewater by using combination of Fenton reagent and activated carbon adsorption. Effect of molar ratio of Fenton reagent, $\mathrm{pH}$, and reaction time on COD degradation were also examined.

\subsection{METHODOLOGY}

\subsection{Chemical and Materials}

Sample of rubber industrial wastewater was taken from raw rubber or latex washing process at second unit of washing process in one of rubber factory in Palembang, South Sumatera, Indonesia. Hydrogen peroxide $\left(\mathrm{H}_{2} \mathrm{O}_{2} 30 \% \mathrm{w} / \mathrm{w}\right)$, Ferrous sulphate catalyst $\left(\mathrm{FeSO}_{4} 7 \mathrm{H}_{2} \mathrm{O}\right.$ ) and other chemicals were purchased from Sigma Aldrich. Granular activated carbon was supplied from distributor in Jakarta.

\subsection{Procedures}

Experiments were carried out in batch mode in an oxidation reactor. For every experiment performed, the reactor was initially loaded with rubber wastewater sample solution, adding Ferrous sulphate catalyst, following by adjusting $\mathrm{pH}$ value of 3.5 with 0.1 or $0.01 \mathrm{M}^{\circ} \mathrm{H}_{2} \mathrm{SO}_{4}$ and $0.1 \mathrm{M}$ of $\mathrm{NaOH}$ solution. Concentration of Hydrogen peroxide was varied while the Ferrous sulphate concentration was kept constant to make the $\left[\mathrm{Fe}^{2+}\right] /\left[\mathrm{H}_{2} \mathrm{O}_{2}\right]$ molar ratio of 1:150-1:250. Continuous stirring speed of $200 \mathrm{rpm}$ was maintained by means of mechanical stirrer. The samples were withdrawn periodically for $\mathrm{pH}$, TSS, and COD analysis. After reacting sample of rubber wastewater in the reactor, the sample then contacting with $20 \mathrm{~cm}$ height of activated carbon in an adsorption column for an hour. The remained samples solution were collected for final analysis.

\subsection{Analytical Methods}

The samples were taken periodically for analysis of $\mathrm{pH}$, TSS, and COD degradation. Measurement of $\mathrm{pH}$ was obtained from a Hanna instrument $\mathrm{pH}$ meter. TSS degradation was determined by gravimetric method while COD degradation was determined by titrimetric method [12]. The COD degradation percentage is define as follows:

COD degradation $(\%)=\left(C_{1}-C_{1} C_{0}\right) / C O D_{0} \times 100 \%$ (2)

Where CODo is initial concentration of COD $(\mathrm{mg} / \mathrm{l})$ and $\mathrm{COD}_{+}$is the concentration of COD $(\mathrm{mg} / \mathrm{l})$ at reaction time $\dagger(\mathrm{min})$.

\subsection{RESULTS AND DISCUSSION}

The rubber wastewater sample was examined before handling with Fenton Reagent and activated carbon adsorption. The analyses results were compared to maximum level of national regulation standard and tabulated in Table 2. As can be seen in the Table 2, all parameter exceeded the maximum level permitted, except $\mathrm{pH}$. Therefore it is important to treat the rubber wastewater in order to meet the 
environmental quality standard before discard to water body.

The rubber wastewater treatment was carried out by Fenton reagent oxidation method, and followed by activated carbon adsorption. In this study, Fenton reagent molar ratio and reaction time were varied, whereas $\mathrm{pH}$ and COD parameters were observed. In order to accomplish maximum removal with minimum doses, effect of Fenton molar ratio should be given importance [13].

Table 2 Results of rubber wastewater sample analyses

\begin{tabular}{|c|c|c|}
\hline Parameter & Value & $\begin{array}{c}\text { Maximum Level } \\
\text { (South Sumatera } \\
\text { Provincial Regulation No. } \\
\text { 8/2012 for Rubber } \\
\text { Industry) }\end{array}$ \\
\hline $\mathrm{pH}$ & 6.38 & $6-9$ \\
\hline COD & 5613 & 200 \\
\hline$B O D$ & 2925 & 60 \\
\hline TSS & 4290 & 100 \\
\hline $\mathrm{NH}_{3}-\mathrm{N}$ & 202.2 & 5 \\
\hline $\mathrm{N}-$ Total & 404 & 10 \\
\hline
\end{tabular}

All units are $\mathrm{mg} / \mathrm{l}$, except $\mathrm{pH}$

Effect of Fenton molar ratio on COD degradation in treatment of rubber wastewater by using Fenton reagent illustrated in Figure 1. As can be seen in the figure, Fenton oxidation method can reduce COD content in wastewater sample. This explains the strong oxidizing agent $(\mathrm{HO} \cdot)$ can degrade organic or inorganic pollutants from rubber wastewater close to the water quality standards of rubber industry. Degradation of COD increase with increasing Fenton molar ratio applied in this research. Because the higher Fenton molar ratio, more hydroxyl radicals were generated. The best results from the use of Fenton reagent is when using Fenton molar ratio of 1:250 in which the rubber wastewater COD could be lowered to $260 \mathrm{mg} / \mathrm{l}$. Reference [13] reported their work on importance of molar Fenton ratio in Fenton's treatment of a carpet dyeing wastewater that the least amount of Fenton's reagent requisite was for the ratio of 1:192 which up to $95 \%$ of COD removal was reached.

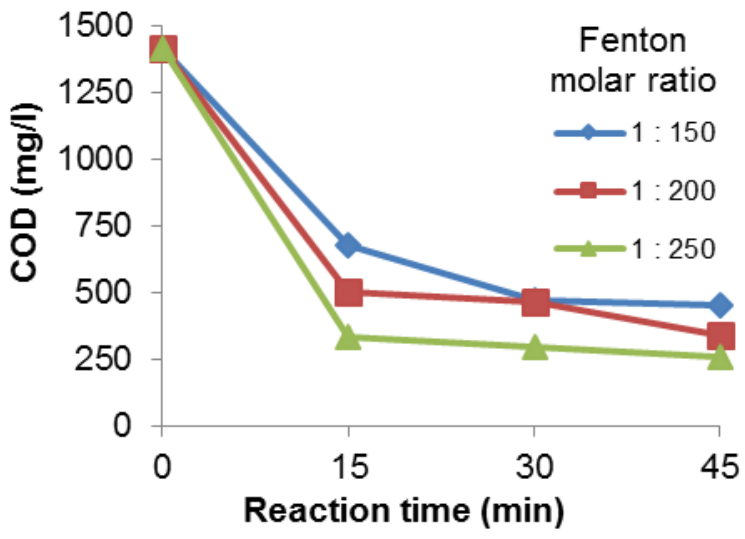

Figure 1 Effect of Fenton molar ratio on COD degradation in treatment of rubber wastewater by using Fenton reagent

To make an economically wastewater treatment plant, it is need to utilize a lower reactant concentration and a shorter reaction time. Effect of reaction time on COD degradation in various molar Fenton ratio was demonstrated in Figure 2 . Percentage of COD degradation increase with increasing reaction time. This result is in agreement with [14], which is in their study by using synthetic wastewater, COD removal of $95 \%$ was obtained within 10 minutes of reaction. However, after 30 minutes of reaction, COD degradation was not significant anymore for all Fenton molar ratio applied in this study. It is clear from the figure, that the Fenton molar ratio of 1:250 is the best, indicated by the highest COD degradation of $82 \%$ can be achieved within 45 minutes of reaction.

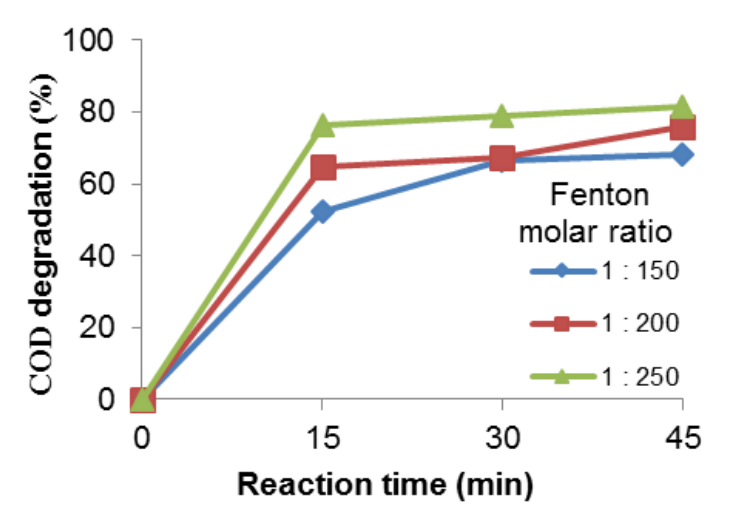

Figure 2 Effect of reaction time on COD degradation in treatment of rubber wastewater by using Fenton reagent

It is well known that Fenton reactions were $\mathrm{pH}$ sensitive and acidic condition was necessary for iron solubility. Therefore, the initial $\mathrm{pH}$ value has to be in the acidic range $(2-4)$ to generate the maximum amount of $\mathrm{HO} \cdot$ to oxidize organic compounds [13]. Significant reaction on Fenton process occurring at pH 3 was informed in many articles [15]. In this study, 
initial $\mathrm{pH}$ of 3.5 was adjusted to untreated rubber wastewater before running. However, COD reduction process using Fenton reagent alone was not meet standard of regulation, in which the final COD of 260 $\mathrm{mg} / \mathrm{l}$, and $\mathrm{pH}$ of 3.7 was detected as shown in Figure 3. Thus in order to meet environmental quality standards for COD and $\mathrm{pH}$ values, the wastewater is still need to be further processed in this case by using activated carbon adsorption.

Figure 4 presented that the use of activated carbon as second treatments was essential for lowering the COD to meet the standard of rubber industrial waste. The combination of Fenton reagent and activated carbon treatment was able to lower the value of COD less than $200 \mathrm{mg} / \mathrm{l}$.

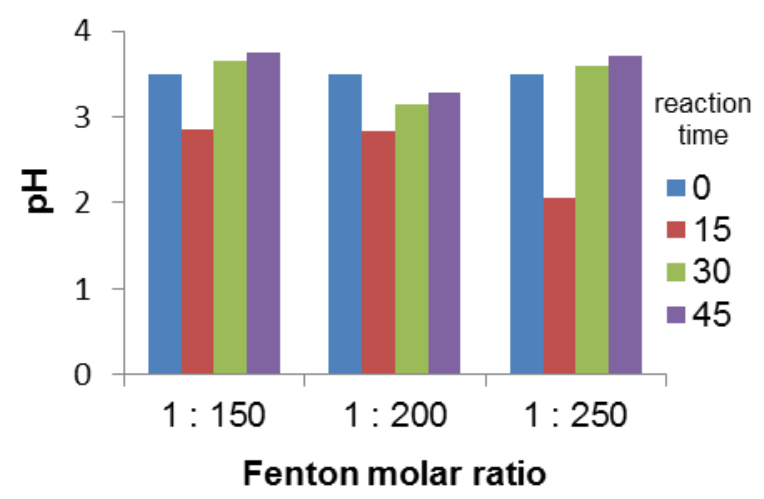

Figure 3 Evaluation of $\mathrm{pH}$ in treatment of rubber wastewater by using Fenton reagent

By using combination of Fenton reagent and activated carbon adsorption, the highest COD degradation of $95 \%$ was reached by means of Fenton molar ratio of 1:250 as displayed in Figure 5. The role of activated carbon can adsorb pollutants which were difficult degraded by $\mathrm{HO}$ • hydroxyl ions, therefore can decrease COD value until $71 \mathrm{mg} / \mathrm{l}$.

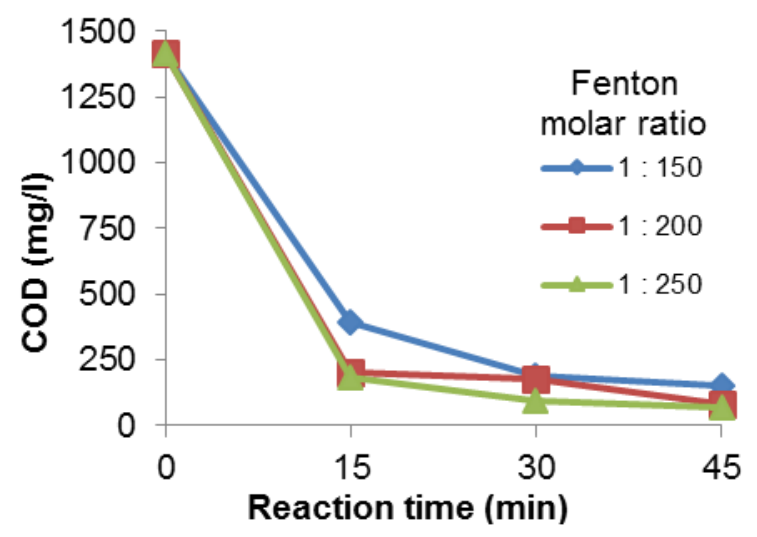

Figure 4 Effect of Fenton molar ratio on COD degradation in treatment of rubber wastewater by using Fenton reagent and activated carbon adsorption
The use of activated carbon not only contribute to lower the COD value of rubber wastewater but also to raise the $\mathrm{pH}$ value, where a $\mathrm{pH}$ range of 6.8 to 7.8 was identified after adsorbed as described in Figure 6. The increase in $\mathrm{pH}$ indicated that the acid compound of pollutants can be adsorbed by activated carbon hence the $\mathrm{pH}$ of final products meet the need of wastewater effluent quality standard.

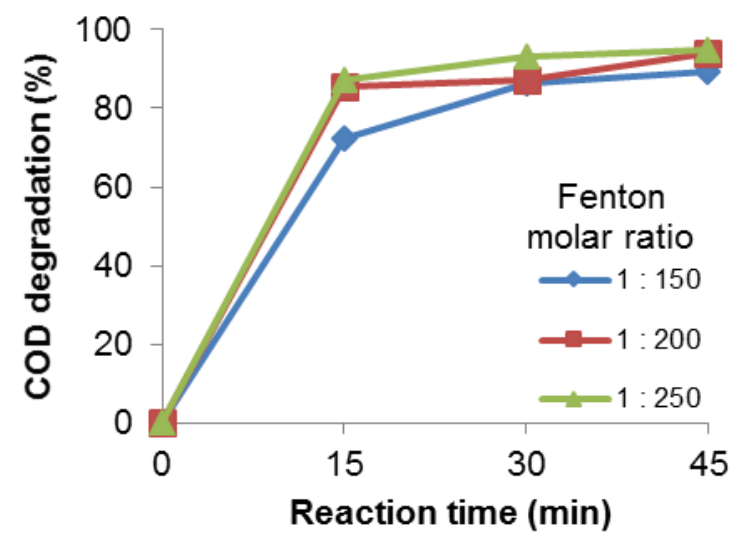

Figure 5 Effect of reaction time on COD degradation in treatment of rubber wastewater by using Fenton reagent and activated carbon adsorption

In this study, the final COD value of $71 \mathrm{mg} / \mathrm{l}$, TSS of $70 \mathrm{mg} / \mathrm{l}$, and $\mathrm{pH}$ value of 7.8 were found by using a combination of Fenton reagent and activated carbon adsorption, with a molar ratio of reagent Fenton 1:250 and reaction time of 45 minutes. These results has fulfilled the provincial regulation for rubber wastewater in South Sumatera, Indonesia. Other study conducted by [16], has been investigated the use of combination of Fenton's reaction and anaerobic treatment of Fenton process for the pretreatment of olive mill wastewater. In their research, COD removal up to $83 \%$ was achieved, at $\mathrm{pH}$ values ranging from 2 to 3 (initial COD of 23400 $\mathrm{mg} / \mathrm{l}$, reaction time of $90 \mathrm{~min}, \mathrm{H}_{2} \mathrm{O}_{2} / \mathrm{Fe}^{2+}$ of 10 ). In another study, Fenton's oxidation has been applied for the pretreatment of landfill leachate [17]. Reference [17] reported that under optimal conditions (initial COD of $10915 \mathrm{mg} / \mathrm{l}$, reaction time of $120 \mathrm{~min}, \mathrm{H}_{2} \mathrm{O}_{2} / \mathrm{Fe}^{2+}$ of $13 \mathrm{w} / \mathrm{w}, \mathrm{pH}$ of 3.2 ) almost $50 \%$ COD removal was observed. 


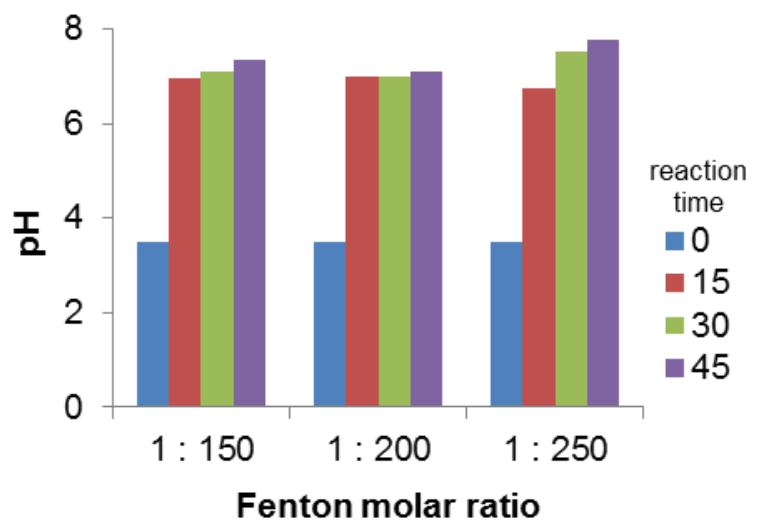

Figure 6 Evaluation of $\mathrm{pH}$ in treatment of rubber wastewater by using Fenton reagent and activated carbon adsorption

It is advisable to use Fenton methods as pretreatment to reduce the toxicity to a certain level beyond which biological treatment can be employed. These combined methods expected to reduce the reactor size and decrease the operating cost [18]. However, various Fenton-based methods may be combined in various manners to obtain maximum efficiency either in pre-treatment or posttreatment.

So far, Fenton's reactions have been extensively used for the removal of COD, TOC, dyes, phenolic compounds, endocrine disrupting chemicals and other recalcitrant organic chemicals from various industrial and municipal wastewater. The major factors affecting these processes including initial concentration of the target compounds, amount of oxidation agents and catalysts, time process, and the nature of the wastewater's solution $(\mathrm{pH}$, presence of solids and other ions) [19]. Therefore different optimum operational conditions can be recognized for various Fenton's wastewater treatment applied in the study.

\subsection{CONCLUSION}

Treatment of rubber industry wastewater was done by using combination of Fenton reagent and activated carbon adsorption. The effect of molar Fenton ration and reaction time were evaluated in term of COD degradation. A Fenton molar ratio of 1:250 is the best, indicated by the highest COD degradation of $82 \%$ can be achieved within 45 minutes of reaction when utilizing Fenton reagent treatment alone. By using a combination of Fenton reagent and activated carbon adsorption, the highest COD degradation of $95 \%$ was reached by means of Fenton molar ratio of 1:250. The addition of activated carbon adsorption treatment can increase the percentage of COD reduction of wastewater rubber. The final COD of $71 \mathrm{mg} / \mathrm{l}$, TSS of $70 \mathrm{mg} / \mathrm{l}$, and
$\mathrm{pH}$ of 7.8 were found which meet environmental quality standards in Indonesia.

\section{Acknowledgement}

The authors thank to the Waste Treatment Technology Laboratory, Chemical Engineering Department, Sriwijaya University.

\section{References}

[1] Z. Xiaofei. 2008. A Study on Countermeasure for Labor Force Shortage in Natural Rubber Industry with Reference To China-ASEAN Region Integration. Int. Conf. ChinaASEAN Reg. Integr. Polit. Econ. Trade, Growth Invest. University of Malaya.

[2] I. O. Asia, E. E. Akporhonor. 2007. Characterization and Physicochemical Treatment of Wastewater from Rubber Processing Factory. Int. J. Physic Sci. 2: 61-67.

[3] M. Mohammadi, H. C. Man, M. A. Hassan, P. L. Yee. 2010. Treatment of Wastewater from Rubber Industry in Malaysia. 9: 6233-6243.

[4] N. H. Nguyen, T. T. Luong. 2012. Situation of Wastewater Treatment of Natural Rubber Latex Processing in the Southeastern Region, Vietnam. J. Vietnamese Environ. 2: 58-64. doi:10.13141/jve.vol2.no2.pp58-64.

[5] H. P.J. S. Pillai, K. Girish. 2014. Rubber Processing Industry Effluent Treatment Using a Bacterial Consortium. Int. J. Curr. Microbiol. Appl. Sci. 3: 775-782.

[6] N. M. N. Sulaiman, S. Ibrahim, S. L. Abdullah. 2010. Membrane Bioreactor for the Treatment of Natural Rubber Wastewater. Int. J. Environ. Eng. 2: 92-109.

[7] B. John, O. James. 2009. Applications of Advanced Oxidation for Wastewater Treatment. WPI's US-Africa Roundtable Conf., Worcester Polytechnic Institute.

[8] P. R. Gogate, A. B. Pandit. 2004. A Review of Imperative Technologies for Wastewater Treatment I: Oxidation Technologies at Ambient Conditions. 8: 501-551. doi:10.1016/S1093-0191(03)00032-7.

[9] N. Rungruang, S. Babel. 2008. Treatment of Natural Rubber Processing Wastewater by Combination of Ozonation and Activated Sludge Process. Proceed-Ing Int. Conf. Environ. Re-Search Technol. (ICERT 2008). Parkroyal, Penang, Malaysia. 259-263.

[10] T. E. Agustina. 2013. AOPs Application on Dyes Removal, in: S.K. Sharma, R. Sanghi (Eds.). Wastewater Reuse Manag. Springer, Dordrecht. 353-372. doi:10.1007/978-94007-4942-9.

[11] M. S. Lucas. 2006. Decolorization of the Azo Dye Reactive Black 5 by Fenton and Photo-Fenton Oxidation. 71: 236244. doi:10.1016/j.dyepig.2005.07.007

[12] APHA, AWWA, WEF. 2012. Standard Method for the Examination of Water and Wastewater. 22nd ed.

[13] I. Gulkaya, G. A. Surucu, F. B. Dilek. 2006. Importance of $\mathrm{H} 2 \mathrm{O} 2 / \mathrm{Fe} 2+$ ratio in Fenton's Treatment of a Carpet Dyeing Wastewater. 136: 763-769. doi:10.1016/j.jhazmat.2006.01.006.

[14] T. E. Agustina, Y. Wijaya, F. Mermaliandi. 2016. Degradation of Reactive Red 2 by Fenton and PhotoFenton Oxidation Processes. 11: 5227-5231.

[15] C.-Y. Chang, Y.-H. Hsieh, K.-Y. Cheng, L.-L. Hsieh, T.-C. Cheng, K.-S. Yao. 2008. Effect of pH on Fenton Process Using Estimation of Hydroxyl Radical with Salicylic Acid as Trapping Reagent. Water Sci. Technol. 58: 873-879. doi:10.2166/wst.2008.429.

[16] F. A. El-gohary, M. I. Badawy, M. El-khateeb, A. S. El-Kalliny. 2009. Integrated Treatment of Olive Mill Wastewater (OMW) by the Combination of Fenton's Reaction and 
Anaerobic Treatment. J. Hazard. Mater. 162: 1536-1541. doi:10.1016/j.jhazmat.2008.06.098.

[17] D. Petruzzelli, G. Boghetich, M. Petrella, A. Dell'erba, P. L'abbate, S. Sanarica, M. Miraglia. 2007. Pre-treatment of Industrial Landfill Leachate by Fenton's Oxidation, Global. 9: 51-56.

[18] A. Babuponnusami, K. Muthukumar. 2014. A Review on Fenton and Improvements to the Fenton Process for
Wastewater Treatment. J. Environ. Chem. Eng. 2: 557-572. doi:10.1016/j.jece.2013.10.011.

[19] A. S. Stasinakis. 2016. Use of Selected Advanced Oxidation Processes (AOPs) for Wastewater Treatment - A Mini Review. Glob. Nest J. 10: 376-385. 
79:7-2 (2017) 31-37 | www.jurnalteknologi.utm.my | elSSN 2180-3722 | 
